\title{
Comparison of the Performances of Absorption Refrigeration Cycles with Weak and Strong Ammonia-Water Solution
}

\author{
Mislav Sentić ${ }^{1}$, Ladislav Lazić ${ }^{2 *}$ \\ 1 INA d.d., Avenija Većeslava Holjevca 10, 10000 Zagreb, Croatia \\ ${ }^{2}$ University of Zagreb, Faculty of Metallurgy; Aleja narodnih heroja 3, 44103 Sisak, Croatia
}

\begin{abstract}
The absorption refrigeration system differs fundamentally from vapour compression system only in the method of compressing the refrigerant. So-called thermal-compressor, which consists of an absorber, generator and pump, replace the compressor of a vapour compression system. For heating process, instead electric energy, thermal energy in the form of saturated steam, hot water, natural gas or the waste heat sources are being used. In this article, on the example of single-effect absorption system using ammonia-water solution with ammonia as the refrigerant and water as the absorbent, research has been devoted to investigate theoretically the performance of two different operating modes of absorption refrigeration process with weak and strong ammonia-water solution in the generator.
\end{abstract}

Keywords: absorption, refrigeration, ammonia-water, strong, weak, solution, COP.

\section{Introduction}

Current trends in development countries show that the rational energy use and managing is basic presumption of sustainable development. Energy management today is based on the use of clean and energy efficient technologies as well as renewable heat sources with purpose of environmental protection. One of the energy efficient methods is the absorption refrigeration process, which uses heat energy directly for cooling purposes [1-3].

Although vapour compression systems still dominate all market sectors, absorption systems provide many advantages. It operates with added heat energy supplied from any source, which is at a sufficiently high temperature and does not require high-grade and expensive energy. Heat rejected to the surrounding as waste after the most of industrial process can be used in an absorption refrigeration cycle. Therefore, the main advantage of absorption refrigeration system is use of low grade energy like heat of e.g. saturated steam, hot water and exhaust systems from I.C. engines, etc. The mechanical compressor is replaced with so-called thermal-compressor, which consists of absorber, generator and circulating pump. It is necessary to use binary mixture for thermal-compressor operation instead of simple operating substance. Moving parts are only in the pump, which is a small element of the system. The work input for the pump is negligible so that electricity consumption in relation to the conventional vapour compression refrigerators is substantially reduced. In this way, the problems related to greenhouse effect from $\mathrm{CO}_{2}$ emission from the combustion of fossil fuels in utility power plants are reduced. 
An additional advantage of absorption systems is the working fluid. Namely, conventional vapour compression systems use chlorofluorocarbon refrigerants, the use of which is limited due to depletion of the ozone layer. Absorption systems have been extensively paid attention in recent years due to the potential for CFC and HCFC replacements in refrigeration, heating and cooling applications [4]. Furthermore, thanks to the progressive reduction of both installation and maintenance cost and energy consumption, their employment may become more and more diffuse [5]. Also, automatic operation for controlling the capacity is much easier in relation to compression system.

\section{Principle of operation}

A single-effect absorption refrigeration system is the simplest and most commonly used design. Main components in absorption refrigeration are: generator, absorber, condenser, evaporator and the circulating pump. In order to increase the system energy efficiency the solution heat exchanger (SHE) and refrigerant heat exchanger (RHE) are added. Figure 1 shows the schematic diagram of a vapor absorption system.

Absorption refrigeration system operates on two pressure levels: high pressure $(p)$ in generator and condenser and low pressure $\left(p_{0}\right)$ in evaporator and absorber. Ammonia vapour is produced in the generator at high pressure from the strong solution of $\mathrm{NH}_{3}$ by an external heating source leaving the generator (point 5) before reaching the condenser [6]. High pressure $\mathrm{NH}_{3}$ vapour is condensed in the condenser, and pressure needs to be so high that vapour could be condensed with cooling water. Condensed ammonia vapour (point 6) is precooled in the refrigerant heat exchanger (RHE) between the condenser and the evaporator to increase the heat of evaporation (point $6 \mathrm{~d}$ ). Precooled $\mathrm{NH}_{3}$ solution is passed through a throttle valve and the pressure and temperature of the refrigerant are reduced below the pressure and temperature to be maintained in the evaporator (point 7). The low temperature refrigerant enters the evaporator and absorbs heat from the fluid being cooled (air or water) and as resulting low-pressure vapour passes to the absorber (point 8d). Slightly superheated, low pressure $\mathrm{NH}_{3}$ vapour is absorbed by the weak solution of $\mathrm{NH}_{3}$, which is sprayed in the absorber. Weak $\mathrm{NH}_{3}$ solution (point 2) entering the absorber becomes strong solution after absorbing $\mathrm{NH}_{3}$ vapour and then it is pumped (point 1) to the generator through the heat exchanger. The pump increases the pressure of the strong solution to generator pressure. The strong $\mathrm{NH}_{3}$ solution coming from the absorber (point 4) absorbs heat from high temperature weak $\mathrm{NH}_{3}$ solution in the heat exchanger. The solution in the generator becomes weak as $\mathrm{NH}_{3}$ vapour comes out of it. The weak high temperature ammonia solution from the generator (point 2) is passed to the heat exchanger through the throttle valve to be reduced to the absorber pressure (point 3). A solution heat exchanger (SHE) is included in the cycle in order to improve system performance.

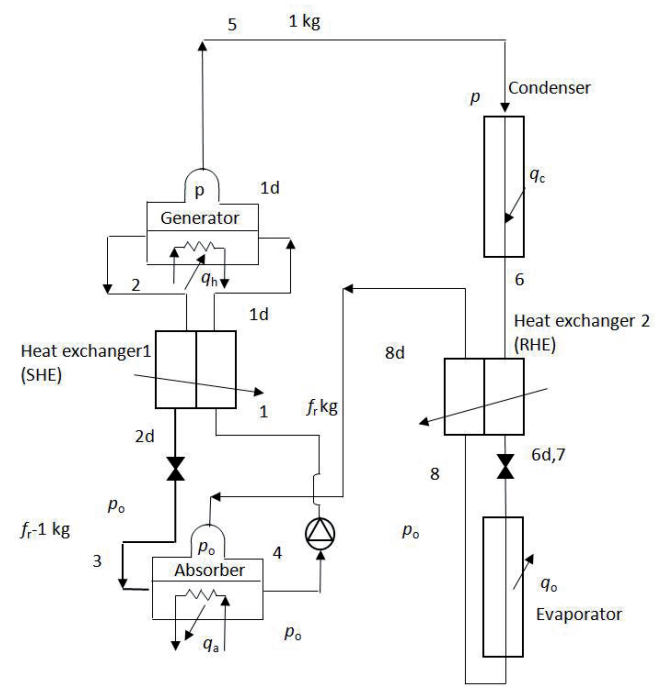

Fig. 1: Single-effect absorption refrigeration system with heat exchangers [7].

The process of heat exchanging in the absorption refrigeration consists of the heat added to the generator at a high temperature and pressure level, the refrigeration at a low temperature and pressure level, the heat extracted in the condenser at an intermediate temperature level and high pressure, and the heat extracted from the absorber at an intermediate level and low pressure.

\section{Model of calculation}

Theoretical process of the single- effect absorption refrigeration system is presented in Merkel h- $\xi$ diagram in Figure 2. 


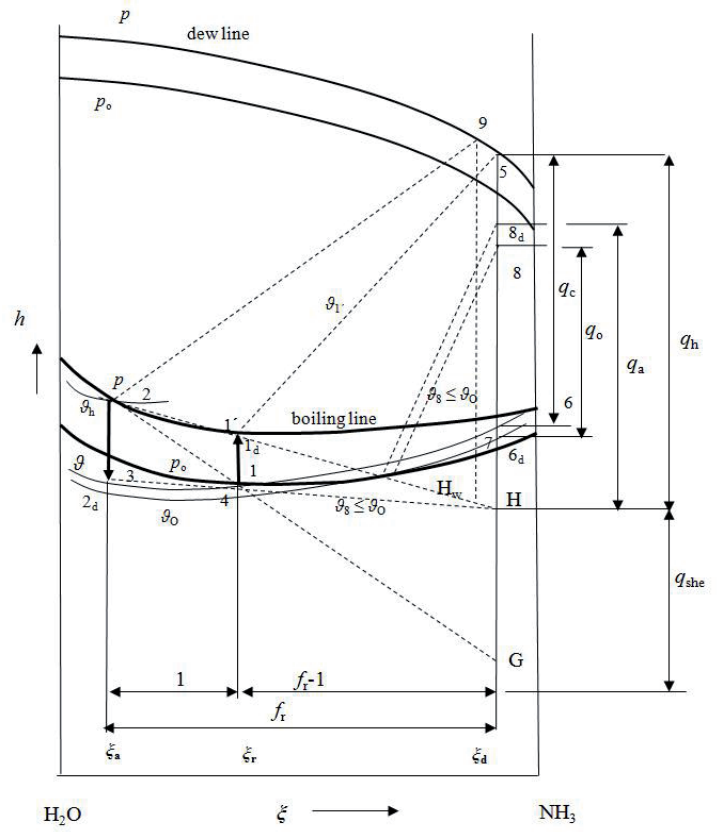

Fig. 2: Single-effect absorption refrigeration cycle with heat exchangers in Merkel h- $\xi$ diagram [7].

Absorption refrigeration system is defined with added heat temperature $\left(\vartheta_{\mathrm{h}}\right)$, cooling water temperature $(\vartheta)$, and refrigeration temperature $\left(\vartheta_{\circ}\right)$.

In the ideal case may be assumed the following assumptions:

- The temperature $\vartheta_{\mathrm{h}}$ is equal to the temperature $\vartheta_{2}$ of weak saturated solution,

- The refrigeration temperature, evaporation temperature and precooled temperature are similar $\vartheta_{6 \mathrm{~d}}=\vartheta_{8}=\vartheta_{0}$

- The temperature of cooling water $\vartheta$ is equal to the absorber temperature $\vartheta_{4}\left(\vartheta=\vartheta_{4}\right)$,

- The temperature of solution after SHE $\left(\vartheta_{1 \mathrm{~d}}\right)$ [8] is very close or equal to saturated strong solution temperature in the generator and no vapour generation takes place in SHE.

The heat energy balance expression per $\mathrm{kg}$ of produced vapour ( $\mathrm{kJ} / \mathrm{kg}$ vapour) for absorption refrigeration is:

$q_{\mathrm{h}}+q_{0}=q_{\mathrm{c}}+q_{\mathrm{a}}, \quad \mathrm{kJ} / \mathrm{kg}$

The values of individual members in Eq. (1) were determined according to the Merkel h- $\xi$ diagram (Fig. 2): $\checkmark$ For strong solution

$q_{\mathrm{h}}=h_{5}-h_{\mathrm{H}}, \quad \mathrm{kJ} / \mathrm{kg}$

$q_{\mathrm{c}}=h_{5}-h_{6}, \quad \mathrm{~kJ} / \mathrm{kg}$

$q_{0}=h_{8}-h_{7}, \quad \mathrm{~kJ} / \mathrm{kg}$

$q_{\mathrm{a}}=h_{8 \mathrm{~d}}-h_{\mathrm{H}}, \quad \mathrm{kJ} / \mathrm{kg}$

$\checkmark$ For weak solution

$q_{\mathrm{h}}=h_{9}-h_{\mathrm{Hw}}, \quad \mathrm{kJ} / \mathrm{kg}$

The added heat for the generator is also calculated by the next equations:

$\checkmark$ For strong solution

$q_{\mathrm{h}}=h_{5}-h_{2}+f_{\mathrm{r}} \cdot\left(h_{2}-h_{1 \mathrm{~d}}\right), \quad \mathrm{kJ} / \mathrm{kg}$

For weak solution

$q_{\mathrm{h}}=h_{9}-h_{2}+f_{\mathrm{r}} \cdot\left(h_{2}-h_{1 \mathrm{~d}}\right), \quad \mathrm{kJ} / \mathrm{kg}$

Values of the enthalpies are read from the Merkel h- $\xi$ diagram [7].

Circulation of strong ammonia solution $f_{\mathrm{r}}(\mathrm{kg} / \mathrm{kg})$ is calculated by the next expression:

$f_{\mathrm{r}}=\frac{\xi_{\mathrm{d}}-\xi_{\mathrm{a}}}{\xi_{\mathrm{r}}-\xi_{\mathrm{a}}}$

Coefficient of Performance (COP) of the singleeffect absorption refrigeration cycle is defined as the next ratio:

$\mathrm{COP}=\frac{\text { cooling capacity obtained at evaporator }}{\text { heat input for the generator }+ \text { work input for the pump }}$

The work input for the pump is negligible relative to the heat input at the generator. Therefore, the pump work is often neglected for the purposes of analysis [2]. Accordingly

$\mathrm{COP}=\frac{q_{0}}{q_{\mathrm{h}}}$

\section{Operating parameters of the single-effect absorption refrigeration system}

In this paper theoretical analysis of the performance of two different operating modes of absorption refrigeration process with weak and strong ammonia-water solution in the generator 
was conducted. For the three in practice possible cases of the operating parameters for absorption refrigeration are presented in Table1. All cases are with the solution and refrigerant heat exchanger.

Table 1: Operating conditions for absorption refrigeration.

Case 1 Case 2 Case 3

\begin{tabular}{|c|c|c|c|}
\hline added heat temperature, $\vartheta_{\mathrm{h}}{ }^{\circ} \mathrm{C}$ & 120 & 120 & 120 \\
\hline $\begin{array}{l}\text { cooling water temperature, } \\
\vartheta^{\circ} \mathrm{C}\end{array}$ & 20 & 20 & 20 \\
\hline refrigeration temperature, $\vartheta_{0}{ }^{\circ} \mathrm{C}$ & 0 & 0 & 0 \\
\hline pressure in generator, $p$ bar & 10 & 15 & 15 \\
\hline pressure in evaporator, $p_{\mathrm{o}}$ bar & 2 & 2 & 2 \\
\hline weak solution concentration $\xi_{\mathrm{a}}$ & 0.219 & 0.295 & \\
\hline $\begin{array}{l}\text { strong solution concentration } \\
\xi_{\mathrm{r}}\end{array}$ & & & 0.46 \\
\hline
\end{tabular}

\section{Results and Discussion}

The results are presented in Table 2.

Table 2: The results of calculations.

\begin{tabular}{|c|c|c|c|}
\hline & $\begin{array}{l}\text { weak } \\
\text { solution } \\
\text { Case } 1\end{array}$ & $\begin{array}{l}\text { weak } \\
\text { solution } \\
\text { Case } 2\end{array}$ & $\begin{array}{l}\text { strong } \\
\text { solution } \\
\text { Case } 3\end{array}$ \\
\hline $\begin{array}{l}\text { Ammonia } \\
\text { vapour } \\
\text { purity }\end{array}$ & $\xi_{\mathrm{d}}=0.86$ & $\xi_{\mathrm{d}}=0.9$ & $\xi_{\mathrm{d}}=0.96$ \\
\hline$h_{5}, \mathrm{~kJ} / \mathrm{kg}$ & & & 1810 \\
\hline$h 9, \mathrm{~kJ} / \mathrm{kg}$ & 2014 & 1960 & \\
\hline$h_{2}, \mathrm{~kJ} / \mathrm{kg}$ & 435 & 430 & 430 \\
\hline$h 1 \mathrm{~d}, \mathrm{~kJ} / \mathrm{kg}$ & 215 & 279 & 279 \\
\hline$h \mathrm{Hw}, \mathrm{kJ} / \mathrm{kg}$ & -150 & -120 & \\
\hline$h \mathrm{H}$ & & & -180 \\
\hline$f_{\mathrm{r}}$ & 2.66 & 3.666 & 4.0303 \\
\hline$q_{\mathrm{h}}, \mathrm{kJ} / \mathrm{kg}$ & $\begin{array}{l}2164.2 \\
E q .(8)\end{array}$ & $\begin{array}{l}2082.6 \\
E q .(8)\end{array}$ & $\begin{array}{l}1988.53 \\
\text { Eq. (7) }\end{array}$ \\
\hline$q \mathrm{~h}, \mathrm{~kJ} / \mathrm{kg}$ & 2164 Eq. (6) & 2080 Eq. (6) & 1990 Eq. (2) \\
\hline$q_{\circ}, \mathrm{kJ} / \mathrm{kg}$ & 870 Eq. (4) & 990 Eq. (4) & 1150 Eq. (4) \\
\hline$q_{c}, \mathrm{~kJ} / \mathrm{kg}$ & 1714 Eq. (3) & 1630 Eq. (3) & 1410 Eq. (3) \\
\hline$q_{\mathrm{a},}, \mathrm{kJ} / \mathrm{kg}$ & 1320 Eq. (5) & 1440 Eq. (5) & 1730 Eq. (5) \\
\hline COP & $\begin{array}{l}0.402 \\
\text { Eq. }(10)\end{array}$ & $\begin{array}{l}0.476 \\
\text { Eq. }(10)\end{array}$ & $\begin{array}{l}0.578 \\
\text { Eq. }(10)\end{array}$ \\
\hline
\end{tabular}

The values of the heat input into the generator calculated by Eqs. (8) and (6) for weak solution as well as by (7) and (2) for strong solution are approximately identical. As seen, the process with weak solution needs the higher value of added heat energy. This is because the generator produces the lower value of purity of $\mathrm{NH}_{3}$ vapour when absorption process operates with weak solution (Case 1). The COP of Case 1 is, when process is operated on 10 bar, only 0.402 because the ammonia vapour purity is 0.86 . Also, when the refrigeration is operated with weak solution at the same temperature, but on higher pressure of 15 bar (Case 2), the added heat for generator is lower. The purity of ammonia vapour is higher and has the value of 0.9. Also, the system energy efficiency is higher, which is evident from higher value of COP. In Case 3 the process operates with strong solution and on 15 bar pressure at the same temperature. The basic advantage of the process with strong solution is higher evaporation in the evaporator and lower added heat into the generator. The ammonia vapour purity $\left(\xi_{\mathrm{d}}\right)$ is highest (0.96) as well as the system energy efficiency. In the Case 3 the value of COP is 0.578 .

\section{Conclusions}

Nowadays rational energy is one of presumption of sustainable development. Use of absorption refrigeration is very often, especially for water chilling. It is very important how to operate absorption refrigeration. This paper illustrates the thermal advantages of the single-effect absorption system using strong ammonia-water solution in relation to the process with weak solution.

The advantages are the following:

- Lower heat input into the generator,

- Refrigeration capacity of the evaporator is higher at the same evaporation pressure,

- Purity of ammonia vapour is higher,

- Higher Coefficient of Performance (COP),

It may be concluded that the single-effect absorption system needs to operate with strong solution and at high pressure.

\section{Nomenclature:}

$f_{\mathrm{r}}$ - circulation of ammonia strong solution $(\mathrm{kg} / \mathrm{kg})$ $h_{5}$ - enthalpy of ammonia vapour refrigerant operated in balance with strong solution

$h_{9}$ - enthalpy of ammonia vapour refrigerant operated in balance with weak solution 
$h_{\mathrm{H}}$ - enthalpy of ammonia at the inlet of the generator (strong solution)

$h_{\mathrm{Hw}}$ - enthalpy of ammonia at the inlet of the generator (weak solution)

$h_{2}$ - enthalpy of weak ammonia solution in the generator

$h_{1 d}$ - enthalpy of strong ammonia solution after the heat exchanger (SHE)

$q_{\mathrm{h}}$-heat input (added heat) into the generator, $\mathrm{kJ} / \mathrm{kg}$

$q_{0}$ - extracted heat for the evaporator, $\mathrm{kJ} / \mathrm{kg}$

qc - released cooling heat from the condenser, $\mathrm{kJ} / \mathrm{kg}$

$q_{\mathrm{a}}$ - released cooling heat from the absorber, $\mathrm{kJ} / \mathrm{kg}$

$q_{\text {SHE }}$ - energy saving, $\mathrm{kJ} / \mathrm{kg}$

$\vartheta_{\mathrm{h}}$ - added heat temperature, ${ }^{\circ} \mathrm{C}$

$\vartheta$ - cooling water temperature, ${ }^{\circ} \mathrm{C}$

$\vartheta_{0}$ - refrigeration temperature, ${ }^{\circ} \mathrm{C}$

$\xi_{\text {a }}$ - concentration of ammonia in weak ammoniawater solution

$\xi_{\mathrm{r}}$ - concentration of ammonia in strong ammoniawater solution

$\xi_{\mathrm{d}}$ - concentration of ammonia vapour

\section{References and Notes}

[1] Ziegler, F (1999). Recent developments and future prospects of sorption heat pump system. International Journal of Thermal Science, 38, pp.191-208.

[2] Srikhirin, P, Aphornratana, S, Chungpaibulpatana, S ( 2001). A review of absorption refrigeration technologies, Renewable and Sustainable Energy Reviews, 5, pp. 343-372.

[3] Mohideen, S.T, Renganarayanan, S (2006). Heat and mass transfer studies on 134 A-DMAC based falling film absorbers for absorption refrigeration system, Proceedings of the $4^{\text {th }}$ WSEAS Int. Conf. on Heat Transfer, Thermal Engineering and Environment, Elounda, Greece, pp. 342-350.

[4] Poberžnik, S, Goricanec, D, Krope, J (2007). Traditional vs. alternative energy house heating source, Proceedings of the 2ndIASME / WSEAS International Conference on Energy \& Environment (EE'07), Portoroz, Slovenia, pp. 15-17.

[5] Feng X, Goswami D.Y (1999). Thermodynamic Properties of ammonia-water mixtures for Power-cycle application, Energy, 24, pp. 525-536.

[6] Sun, D (1998). Comparison of the performances of NH3$\mathrm{H} 2 \mathrm{O}, \mathrm{NH} 3-\mathrm{LiNO} 3$ and $\mathrm{NH} 3-\mathrm{NaSCN}$ absorption refrigeration systems, Energy Conversion and Management, 39, pp. 357368.

[7] Bošnjaković, F. (1986). Nauka o toplini III, Tehnička knjiga Zagreb

[8] Herold, K.E, Radermacher, R (1995). Absorption chillers and Heat Pumps, CRC Press, Inc., Boca Raton

\section{Biographical notes}

Mislav Sentić, was born 1968 in Croatia. He received degrees in mechanical engineering from the Faculty of Mechanical Engineering and Naval Architecture, University of Zagreb (B.S., 1995). He obtained a Ph.D. in Technical Sciences at the Faculty of Mining, Geology and the Petroleum Engineering, University of Zagreb in 2011. He has been employed in INA d.d. since 1998 where he currently works. He is mechanical expert for process and gas technology, especially for compressors, gas cooling and refrigeration, and energy consumption. The main areas of his professional activities are optimization in process technology, in energy consumption and design mechanical and technological projects. He works as designer on main project, idea project, feasibility and investment studies. He worked in Damascus 2005 in Syria on Jihar field development plan as gas process engineer and project team member. He is a member of Scientific Council for Oil and Gas of Croatian Academy of Sciences and Arts. Also, he is a member in Chamber of Croatian mechanical engineering and Croatian Gas Association. He held the internal course in Hysys computer program in INA d.d. for gas process plant simulation. He was participant of many energy scientific and professional conferences as author.

Ladislav Lazić, prof., was born 1953 in Croatia. He received degrees in mechanical engineering from the Faculty of Mechanical Engineering and Naval Architecture, University of Zagreb (B.S., 1976; M.S. 1984) and in metallurgy engineering from the Faculty of Metallurgy, University of Zagreb (Ph.D., 1991). In 1981 he joined the Faculty of Metallurgy, University of Zagreb. Currently he is a professor of a wide variety of courses in the mechanical engineering, thermal science and industrial furnaces and dean of the Faculty of Metallurgy. The main areas of his scientific activities are design and efficiency of industrial furnaces and heating equipments, CFD approach to combustion modelling and numerical simulation of furnace processes, and the techniques in the reduction of NOX emissions. Prof. L. Lazic is an author/co-author of more than 150 scientific and Prof. L. Lazić is an author/co-author of more than 150 scientific and professional works, including 3 monographs and 1 patent, and 15 projects and studies for industrial requirements. He developed wide international scientific and teaching activity in cooperation with numerous prestigious international scientificeducational institutions and received several national and international awards for teaching and research. 